\title{
E-Readiness of Blockchain Technology in Modernization of Tax Administration in Indonesia
}

\author{
Samuel Martin Fernando Saragih ${ }^{1}$, Milla Sepliana Setyowati ${ }^{2}$ \\ \{samuelsaaragih@gmail.com ${ }^{1}$, milla.s.setyowati@gmail.com² \\ Bachelor Student Department of Fiscal Administration Sciences, Universitas Indonesia, Indonesia ${ }^{1}$ \\ Lecturer, Department of Fiscal Administration Sciences, Universitas Indonesia, Indonesia ${ }^{2}$
}

\begin{abstract}
Tax administration has a vital role in tax system. In consequence, improvement is needed one of which is done by modernizing tax administration. One of modernization of tax administration initiated in Indonesia is using blockchain technology. This thesis aims to describe the benefits, analyze factors, and analyze e-Readiness of blockchain technology usage in modernizing tax administration in Indonesia. This study uses a qualitative approach and qualitative data analysis techniques. From the results of in-depth interviews and literature studies, it is shown some factors that influence the use of blockchain technology in the modernization of tax administration which consist of infrastructure, skills, and government policies. E-Readiness will be reviewed from three perspectives: government policy, infrastructures, and penetration of blockchain technology.
\end{abstract}

Keywords: Blockchain, e-Readiness, Modernization of Tax Administration.

\section{Introduction}

The target of tax revenue in Indonesia in the last ten years has a fairly positive trend. In 2009 state revenues from tax revenues were targeted at 651.95 billion rupiah and in 2018 state revenues from taxes were targeted at 1,618 billion rupiah. The following are data on the target of tax revenue in Indonesia in 2009-2018.

The tax revenue target has a positive trend in the last ten years. If averaged from figure 1 , there is an increase of 107.35 Trillion Rupiah. The figure that is the target of tax revenue can be said to be quite large so that there is a need for good tax administration so that there is an increase in taxpayer compliance in Indonesia.

Increased tax revenue targets are also offset by an increase in taxpayers who report their taxes. Reported from pajak.go.id (2018), it is stated that the tax compliance of the Indonesian people is getting better as evidenced by the increase in the submission of the Annual Tax Returns (SPT) of 10.59 million SPTs as of $31^{\text {st }}$ March 2018 or can be said to grow $14 \%$ compared to with the previous year. The number of taxpayers registered as of March 2018 is $38,651,881$ and $17,653,963$ of them have the obligation to submit tax returns. SPT reporting carried out by Taxpayers has also shifted from submitting manual SPT to electronic SPT. $80.13 \%$ of all SPTs or 8.49 million SPTs per March 2018 are delivered electronically and the rest still submit SPT manually or decrease by $12 \%$ from the previous year. 
This increase in electronic tax reporting is also in line with the existence of an electronic tax payment system as stipulated in Minister of Finance Regulation Number 32 / PMK.05 / 2014 concerning the Electronic State Revenue System. This system is enough to help taxpayers fulfill their tax obligations. However, this system still has disadvantages such as lack of transparency due to information channels that are not spread evenly. This will be very vulnerable to errors and lead to inefficiencies in tax administration.

Online Pajak initiated the use of blockchain technology in order to modernize tax administration in Indonesia as a first step to minimize inefficiencies in tax administration. This is also in accordance with the results of research that says blockchain technology will provide long-term solutions that reduce the administrative burden in the taxation system (Deloitte, 2017). The use of this technology is expected to be used more massively but until now it has not been done. But if you want to use this technology massively, you need system integration. In addition to the integration of information technology systems at various levels, the use of the blockchain system also requires extensive changes in the legal system, and reforms within the legal database, intellectual property, and legal identity.

Before wanting to implement blockchain technology, it is necessary to know the readiness of those who have authority in tax administration. Therefore, this study will analyze the readiness of the use of blockchain technology in the modernization of tax administration in Indonesia. In addition, factors that influence the implementation of blockchain technology in modernizing tax administration in Indonesia will also be examined.

\section{Literature Review}

\subsection{Modernization of Tax Administration}

Tax administration is an entity that manages taxation in one country. The tax administration also implements and enforces tax law and accepts the mandate of the law directly [1]. Alink and Kommer also argue that tax administration, like private companies and other organizations, has a core business (business core), namely collecting and collecting taxes that have been charged in tax law. Good tax administration is efficient and effective tax administration, without these two things the tax policies that have been compiled by the government will be difficult to achieve [2].

Effective information systems are the key to implementing tax collection fairly. Conversely, if the tax administration is not supported by an effective information system, it will lead to inequality in taxation, namely Tax Subjects which should be taxpayers but not registered in tax administration, and vice versa. So, in order to achieve an effective information system in taxation there must be a role and involvement from various parties, both the private sector and the government itself

Modernization in tax administration is very closely related to the use of information technology in tax administration. One of the modernizations that can be done in tax administration is in the field of tax payment / collection [1]. The process of implementing tax collection really requires efficiency in its collection so that it requires fast access to accurate information relating to all aspects of the taxpayer's tax debt itself, which can be used to increase law enforcement. The use of technology and information can increase the effectiveness and efficiency of the tax collection process and in paying tax debts.

Solehzoda [3] argues that there is efficiency in tax collection when using technology both from the tax collector and the taxpayer itself as attached in the following table. 
Table 1. Efficient Use of Technology in Tax Collection from Taxpayers and Tax Authorities

\begin{tabular}{|l|l|}
\hline \multicolumn{1}{|c|}{ Taxpayer } & \multicolumn{1}{|c|}{ Tax Authority } \\
\hline $\begin{array}{l}\text { Reducing the complexity of tax accounting } \\
\text { and tax payment processes and reducing } \\
\text { interactions with tax authorities }\end{array}$ & $\begin{array}{l}\text { Reducing the complexity and costs of } \\
\text { processing and supervising the composition } \\
\text { of tax documentation }\end{array}$ \\
\hline $\begin{array}{l}\text { Provision of information to Taxpayers in } \\
\text { order to resolve problems and procedures } \\
\text { for interaction with tax authorities }\end{array}$ & $\begin{array}{l}\text { Reducing the complexity of the tax debt } \\
\text { monitoring process }\end{array}$ \\
\hline $\begin{array}{l}\text { Integration of internal control systems from } \\
\text { payments and obligations with the tax } \\
\text { administration system }\end{array}$ & $\begin{array}{l}\text { Integration of the internal control system of } \\
\text { payments and obligations with the tax } \\
\text { administration system }\end{array}$ \\
\hline $\begin{array}{l}\text { The ability to view personal information } \\
\text { and access personal accounts online }\end{array}$ & $\begin{array}{l}\text { Reducing employee costs and the cost of } \\
\text { transferring data and information to } \\
\text { Taxpayers }\end{array}$ \\
\hline $\begin{array}{l}\text { Automatic reconciliation and tax } \\
\text { supervision }\end{array}$ & $\begin{array}{l}\text { Able to provide the information to taxpayer } \\
\text { requests by online }\end{array}$ \\
\hline $\begin{array}{l}\text { Able to communicate with tax authorities } \\
\text { through communication channels }\end{array}$ & $\begin{array}{l}\text { Making base metadata with the aim of } \\
\text { monitoring and then analyzing statistical, } \\
\text { tax and economic data }\end{array}$ \\
\hline $\begin{array}{l}\text { Reduction of supervision of internal risk, } \\
\text { administrative risk, and risk of conflict } \\
\text { with the tax authorities }\end{array}$ & $\begin{array}{l}\text { Development of information technology } \\
\text { infrastructure based on metadata to } \\
\text { exchange information with state authorities }\end{array}$ \\
\hline $\begin{array}{l}\text { Cost savings, including excess tax } \\
\text { payments }\end{array}$ & $\begin{array}{l}\text { Reducing the cost of implementing tax } \\
\text { administration }\end{array}$ \\
\hline
\end{tabular}

Based on Table 1. it can be seen that the use of technology in tax collection can provide efficiency from the government and the taxpayer itself. These advantages should be considered by the government to use information systems and technology in taxation, especially in Indonesia. Therefore, modernization is needed regarding the use of technology in the field of taxation.

\subsection{E-Readiness}

Readiness and change are two things that are interrelated. The study of change has developed to date and the interesting thing is the topic of an entity trying to be able to keep up with technological developments, the influence of global markets, denationalization, and deregulation which can all change the environment in an entity. With rapid and complex changes, each entity is expected to have readiness for a change [4]. This research will look at the readiness of the tax authorities and related parties in the context of using blockchain technology in tax administration in Indonesia. Therefore, researchers will use the theory of electronic use readiness (e-Readiness). In general, e-readiness can be interpreted as the ability of an entity in the use of technology, information, and communication [5].

Hanafizadeh, Hanafizadeh and Khodabakhsh [6] in his research stated that the fundamental things that must be done in measuring e-readiness are (a) network and infrastructure access; (b) use and access to technology, information and communication by households and individuals; (c) e-business; (d) e-education; (e) e-government; and (f) basic indicators such as adult literacy rates, net national income per capita, expenditure on research 
and development, and population in one country. [7] mention the components of e-readiness itself, namely network access, network learning, network society, network economy, and network policy. Network access is seen from the availability, cost, and quality of networks, services, and technology, information and communication equipment.

When looking at the previous description, there are things that can be factors in ereadiness in this study. Therefore, it can be concluded that looking at e-readiness can see factors: the availability of network infrastructure; penetration of technology, information and communication; and the existence of policies that encourage the use of technology, information and communication.

\subsection{Blockchain}

Blockchain is a digital ledger that is peer-to-peer in nature from various transactions that can be distributed publicly and privately to its users. The blockchain technology uses a cryptographic mechanism and a consensus to verify transactions that have been carried out, which can ensure the validity of a transaction, prevent the occurrence of multiple transactions, and secure high value transactions in uncertain environments [8]. Blockchain is also often referred to as distributed ledger.

As mentioned earlier, blockchain technology is peer-to-peer, meaning a system consisting of nodes (individuals) that can create resources is directly available to other individuals [9]. This system has the advantage when compared to a centralized system because the interaction will occur directly between individuals who become partners in a network, without any intermediary so that it can save processing time and can intensify costs incurred. Although each user has a contribution of resources with different capacities, each partner has functional and equal capabilities and responsibilities.

\section{Methodology}

The research approach is a plan and procedure for research that covers very broad assumptions to detailed methods in data collection, analysis, and interpretation [10]. In this study, a qualitative approach will be used. According to Creswel [10], a qualitative approach is an approach in order to explore and understand the meaning of individuals or groups related to social problems or humanities.

Based on data collection techniques, this research belongs to the category of research with qualitative techniques. Qualitative data can be in the form of various forms such as images, maps, open-ended interviews, observations, documents, and others [11]. This research will be divided into two data collection techniques, namely literature study and field studies.

In this study, data has been obtained through literature studies and field studies through interviews with resource persons. The data that has been collected is still raw data so there needs to be a more comprehensive analysis first. Raw data will be sorted again and organized into one unit so that it can be managed. Furthermore, processing of important things will be carried out and must be studied and continued with an analysis of the readiness of electronic use of blockchain technology in tax administration in Indonesia.

Field conditions when carried out research related to the readiness of electronic use of blockchain technology in the modernization of tax administration in Indonesia are still at least people who understand blockchain technology. In addition, there is still no in-depth 
research related to the use of this technology. Both are also the limitations of the research conducted because of the difficulty of finding parties who understand blockchain technology and tax administration simultaneously.

\section{Analysis}

This analysis will be divided into two parts, starting from the factors that influence the use of blockchain technology in modernizing tax administration in Indonesia and discuss the analysis of electronic use readiness for blockchain technology. in the modernization of tax administration in Indonesia.

\subsection{Factors Affecting the Use of Blockchain Technology}

The use of blockchain technology in a particular country or region is certainly influenced by various factors. The absence of these factors can be an obstacle to the use of technology, but it can also be the opposite. In this section, we will describe the factors that influence the use of blockchain technology. There are three factors that influence the use of blockchain technology in Indonesia, as follows.

The first factor is infrastructure. Infrastructure is a vital thing when developing a technology. Inevitably, new technology that wants to be used on a large scale requires infrastructure. Therefore, a qualified infrastructure is needed so that the use of blockchain technology can run well. Good infrastructure will influence the sustainability of development and also the use of blockchain technology in tax administration in Indonesia. Knowledge of the infrastructure needed will also help the government to carry out budgeting plans. Knowledge about the infrastructure needed can also measure the extent of the ability of a country to adopt blockchain technology.

As for infrastructure, especially what is needed in using blockchain technology is internet penetration. This is because blockchain technology can only run if it is connected to the internet network. Evenly distributed internet penetration can be done if the internet network infrastructure in Indonesia also supports all Indonesian people - wherever they are to connect to the internet. In addition, the quality of internet speed must also be considered because the blockchain is a technology that works in real time.

Other infrastructure needed is hardware and also software that can be a server from the blockchain network in Indonesia. As is known, the use of blockchain network technology is a technology that is peer-to-peer so that existing data can be seen by nodes in accordance with the consensus that has been made before the making of this technology is running. Tax data stored on the blockchain network is of course confidential data and the data can be said to be a state asset. Therefore, the server that is the center of control of this network must also be in Indonesia. Hardware and software that need to be used as a blockchain network server in Indonesia can also improve the security of existing data

Furthermore, the infrastructure needed is electricity. Electricity is vital because the physical devices used to access or make blockchain network technology must be connected to electricity. Even devices to emit internet signals also need electricity. Electricity is vital in using this technology. Therefore physical infrastructure is needed which can guarantee that every Indonesian community can be connected to electricity. However, it should also be noted that the electricity resource infrastructure must also pay attention to the quality of the environment around it so that there are no negative externalities caused by the existence of this infrastructure. 
The last infrastructure needed is a digital identity. This identity can be used to make transactions that are on the blockchain network. The use of this identity is also a requirement needed to access this network, it is also one proof that the party is a node of the blockchain network.

Identity is one of the media that proves that it is true that this person has transacted on the blockchain network. This is because there is no meeting between parties who transact physically. Therefore, the existence of an identity that really becomes a proof is needed that indeed the transaction carried out is true for the person in question. Regarding taxation, the use of this digital identity can also track that the correct amount of tax that should be paid by taxpayers is correct. This tracking can be done because the identity of the Taxpayer has been recorded when making a transaction.

The second factor is the ability related to the use of blockchain technology. Human resources who have capable capabilities must also be owned because blockchain technology is a new technology. This new technology will create a new industry. This new industry requires people who have capability in the fields related to the blockchain. The capabilities needed in blockchain technology in accordance with the above are capabilities related to programming.

The ability possessed is not only to create blockchain technology developers, but also the ability needed related to the advantages and disadvantages of blockchain technology if it is to be used on a large scale. Therefore, further research and development related to this technology is needed. Research and development also play a role not only to the government and related parties, but also development research related to blockchain technology can educate the public about blockchain technology.

The third factor is government policy. As is known that in using this technology massively, regulations are needed that can regulate the implementation of blockchain technology in tax administration in Indonesia. Policies needed in the use of blockchain technology certainly require certain criteria. One of the criteria needed is a policy that will not distort the development of blockchain technology that must be done.

The policy criteria regarding the use of the next blockchain technology that must be fulfilled are policies based on accurate and clear data. This is needed so that existing policies are in accordance with the existing reality. If the policies made are not based on accurate and clear data, there will be a policy clash and also the technological development that will be carried out.

The final criterion needed is a policy that can minimize the risks inherent in blockchain technology. It takes a way to organize so that the inherent risk is minimized. One way is to make a policy that can protect the parties using this technology. In the context of the blockchain, policies related to the protection of its users are urgently needed

\section{2 e-Readiness of Blockchain Technology in Modernization of Tax Administration in Indonesia}

E-Readiness can be said as an evaluation of the extent to which an entity is prepared to use technology, information, and communication. This can be seen from the qualifications of the entity you want to study. The qualifications can be used as a reference whether the intended entity can participate in an information and communication technology network. In short, readiness for electronic use can be seen as the ability of an entity to use a technology, information, and communication.

As mentioned earlier, blockchain technology is a new technology that still many people are unfamiliar with the technology. Therefore, if you want to see this technology can be used in tax administration in Indonesia, the e-Readiness of this technology is needed. This is 
because if the entities that make policies related to the use of this technology have not been able to use this technology, then the goal of modernizing tax administration using blockchain technology cannot be achieved. Therefore, this research will analyze electronic use readiness which is seen from three things, namely: existing policies related to technology, information, and communication; availability of infrastructure; and penetration of technology, information and communication.

E-Readiness in terms of government policy is done because government policy certainly has a vital role in the use of blockchain technology in tax administration in Indonesia. This happens because all policies regarding taxes must be based on government policies contained in tax regulations. In other words, if blockchain technology wants to be implemented in tax administration in Indonesia, relevant policies and regulations are needed that regulate the validity of the use of this technology within the taxation authority.

Regulations related to the mechanism of blockchain technology have not been explicitly formulated by the relevant authorities. If you look at it to date, the regulations related to the blockchain that have been regulated in Indonesia are still limited to regulations regarding cryptocurrency. Cryptocurrency is a type of application of blockchain technology so that it can be said that related to the blockchain network technology itself there are no regulations.

There are positive things from the absence of regulations regarding blockchain technology in Indonesia. The absence of this regulation can free the developers of blockchain technology due to the absence of restrictions by the government. This is certainly very positive because the freedom to develop blockchain technology also means that it can improve innovation from the use of blockchain technology.

Although the absence of the policy formulated related to blockchain technology in taxation has a positive impact, policy also has a role in increasing the acceleration of the things needed in the development of the blockchain. This is because regulations in a country will be binding and authoritarian, so that the infrastructure needs and people who have qualified and capable quality in the use of this technology can be accelerated as well. Therefore, policies related to this technology have a role in analyzing electronic use readiness.

The thing that is still an obstacle in making these policies is the issue related to the security of blockchain technology when used in tax administration. Fear of misuse of data, and other fears are still a consideration of the government. The level of data security in using blockchain technology in tax administration is still a concern. Therefore, there is a need to increase awareness and also the capabilities related to this technology within the government. This is because there is still a lack of information within the government.

E-Readiness in terms of blockchain infrastructure is done because infrastructure is still a matter of consideration for the government to adopt this technology in Indonesia. Infrastructure in the use of blockchain technology has been mentioned before. The main infrastructure needed to use blockchain technology is the internet because the blockchain network will run when connected to the internet. Therefore, the internet supporting infrastructure must also be capable and evenly distributed so that the use of blockchain technology can be used in tax administration in Indonesia.

Until now the distribution of internet network in Indonesia is still around $65 \%-70 \%$ with even distribution in Western and Central Indonesia. Nevertheless, the government - in this case the Ministry of Communication and Information - has had a project to connect each region from West, Central and East Indonesia. This is done by connecting the backbone connection through fiber optic technology. 
The current internet network infrastructure in Indonesia is still not fully available in all regions in Indonesia. However, the government, in this case the Ministry of Communication and Information as the party that has the duty to guarantee equal distribution of internet access in Indonesia, already has programs and designs that are ready to be executed to ensure the distribution of internet networks in Indonesia has indeed been evenly distributed. This even distribution of internet technology will also support the development of blockchain technology in Indonesia so that it can be used to modernize tax administration in Indonesia.

Other infrastructure needed is electronic devices, both hardware and software, which are used to create servers in Indonesia. This is done so that Indonesian taxation data that is very confidential can be minimized leakage. Because the blockchain technology has not been massively implemented, this server has not been fulfilled in Indonesia.

The infrastructure needed in addition to the internet network is the electricity network. This is because the use of blockchain technology must related to electronic devices. This can be one consideration of the need for a greater amount of electricity supply. Therefore, it can be said that the use of blockchain technology must pay attention to the electricity supply in Indonesia and also the level of electricity consumption in Indonesia.

Based on the Press Release of the Ministry of Energy and Mineral Resources of the Republic of Indonesia Number 322 Pers / 04 / SJI / 2019, it is stated that the electricity system in Indonesia is increasingly reliable and no longer deficit. Although the geographical conditions in Indonesia in the form of islands are the biggest challenges, the government continues to encourage the availability of electricity in various parts of Indonesia. The electricity system in Indonesia is currently interconnected and as of 2018, deficit conditions do not occur again in all existing systems. Therefore, it can be concluded that electricity in Indonesia is not a significant challenge because the electricity supply that is owned can already meet the electricity demand in Indonesia.

Other infrastructure needed is digital identity, in accordance with the previous description, that digital identity is a non-physical infrastructure. The use of digital identity is intended so that every party in the blockchain network has its identity. This can make it easier for all parties to find out who is conducting the transaction. In the tax administration itself, this can also be evidence when you want a tax audit.

The Directorate General of Taxation is currently developing the origin of digital identity in Indonesia by creating Kartin1. Kartin1 is a combination of community identity integrated in one card. So Kartin1 can be a tool to track someone's identity because it is integrated.

Based on this narrative, the actual efforts to integrate a single identity were carried out by several institutions. This will certainly complicate the goal because each institution uses its own way to integrate identity. Of course, this requires cooperation and consensus of each institution that develops this identity integration so that a clear policy is found regarding the mechanism for integrating this identity. This will also be difficult if this single identity is to be used as a basis for creating digital identity on the blockchain network.

Basically, this digital identity can be created by itself if the blockchain system has been used. In terms of tax administration, when blockchain technology is implemented, digital identity will be formed by itself. as a future need, digital identity should have been integrated with population data. This can be achieved when the internet infrastructure has reached $85 \%$. While the facts stated by the Ministry of Communication and Information Technology previously said that Indonesia's internet network infrastructure is still around $65 \%-70 \%$ with a focus still on West and Central Indonesia. Despite this fact, Indonesia still has great hopes of reaching $85 \%$ even more, provided that the programs to be executed can run smoothly according to the plan of the Ministry of Communication and Information. 
E-Readiness in terms of penetration of blockchain technology is carried out in order to determine the extent of penetration of this technology in Indonesia. In this study, the penetration of technology, information and communication will be linked to factors that influence the use of blockchain technology in tax administration, namely the ability factor. This is because the capabilities of individuals and related parties related to the use of blockchain technology can reflect the penetration of blockchain technology to the parties concerned.

The first thing that is needed is literacy regarding blockchain technology. The level of literacy using blockchain technology and other related literacy needs to be known before using blockchain technology. The level of literacy is also one of the indicators in electronic use readiness triggered by [6]. The Fiscal Policy Agency believes that the literacy needed to implement blockchain technology is data security literacy, literacy related to blockchain technology, and also the literacy of the possibility of fraud in the use of blockchain technology. At present within the tax authority, the literacy rate is still quite low due to blockchain technology literacy.

The level of literacy can also be influenced by the development research mentioned earlier. Currently in Indonesia research and development related to the use of blockchain technology, especially in tax administration, is still not available. The party from the Directorate General of Taxation of the Republic of Indonesia also stated that the actual use of this technology in the internal institutions is still in the stage of research and development.

This research and development phase were one of the efforts so that the Directorate General of Taxation, as the authority in the field of taxation, was able to decide on the use of blockchain technology suitable in which part of the modernization of tax administration in Indonesia. This is also in line with the opinion of the Directorate General of Treasury of the Republic of Indonesia, namely the need for further research related to the use of blockchain technology in the administration of state revenues in its institutions.

Research and development regarding this technology is very important to be carried out in order to know more clearly the direction of using blockchain technology in the modernization of tax administration in Indonesia. Although the government specifically has not conducted research and development of technology specifically for blockchain technology, there are already government institutions, the Directorate General of Taxes that are beginning to be interested in using blockchain technology in the modernization of tax administration. Although the direction of development carried out by the Directorate General of Taxes and Online Pajak as the initiator of using blockchain technology in tax administration is different, at least this has a positive impact. The positive impact of this is that the results of the development and perspectives that will be given are getting richer so this will make it easier for the government to determine the use of blockchain technology in the administration where it is most suitable.

Penetration of blockchain technology can also be reflected in the number of parties who have certain capabilities to run blockchain technology. As a new technology, of course there are certain abilities needed to use blockchain technology. The special ability needed to use blockchain technology is basic programming capabilities. But it should be noted that this capability is only needed for stakeholders who provide this technology. When talking about taxation, those who need to have this capability are from tax administration authority institutions in Indonesia such as the Directorate General of Taxes and the Directorate General of Treasury. This is needed by these two institutions because both institutions have the authority to make policies related to the use of blockchain technology in tax administration in Indonesia. In Indonesia alone, human resources who could develop blockchain technology, 
namely those who have basic programming skills, are still very lacking. This is also a challenge that exists in Indonesia to develop blockchain technology in general.

\section{Conclusion}

There are three factors that influence to use blockchain technology in the modernization of tax administration in Indonesia, namely: government policy, infrastructure, and capabilities related to blockchain technology. Related to the analysis of the e-Readiness of blockchain technology in the modernization of tax administration can be seen from three things, namely government policy, infrastructure, and the determination of blockchain technology. Judging from government policy, there is still no government policy that explicitly regulates the use of blockchain technology specifically in tax administration in Indonesia. When viewed from infrastructure, infrastructure is still needed which becomes an instrument to run blockchain technology in Indonesia. Whereas when viewed from the penetration of blockchain technology in Indonesia, it can be seen that the penetration of blockchain technology is still quite low.

\section{$6 \quad$ Limitation and Study Forward}

This research is only limited to the analysis of electronic use readiness for blockchain technology. It can be said that the analysis of the implementation and model of blockchain technology use in the future is not included in this study. Therefore, it is expected that in the future there will be research that develops the model of blockchain technology use in the modernization of tax administration.

\section{References}

[1] M. Alink and V. Van Kommer, Handbook on tax administration. IBFD, 2011.

[2] R. Mansury, "Pajak Penghasilan Lanjutan," Jakarta Ind-Hill Co, 1996.

[3] A. Solehzoda, "Information technologies in the tax administration system of VAT," J. Adv. Res. Law Econ., vol. 8, no. 26, pp. 1340-1344, 2017.

[4] A. E. Rafferty, N. L. Jimmieson, and A. A. Armenakis, "Change readiness: A multilevel review," J. Manage., vol. 39, no. 1, pp. 110-135, 2013.

[5] S. Ghosh Roy and P. Upadhyay, "Does e-readiness of citizens ensure better adoption of government's digital initiatives? A case based study," J. Enterp. Inf. Manag., vol. 30, no. 1, pp. 65-81, 2017.

[6] M. Hanafizadeh , P., Hanafizadeh, M. R., \& Khodabakhshi, "Taxonomy of E-Readiness Assessment Measures.," Int. J. Inf. Manag., pp. 180-195, 2009.

[7] R. Budhiraja and S. Sachdeva, "E-readiness assessment (India)," On-line http//unpan1. un. org/intradoc/groups/public/documents/APCITY/UNPAN014673. pdf, 2002.

[8] J. R. Michael, J W, Cohn, Alan, \& Butcher, "Blockchain Technology," Journal, pp. 35-44, 2018.

[9] D. Drescher, "Blockchain basics: A non-technical introduction in 25 steps. Blockchain Basics: A Non-Technical Introduction in 25 Steps." 2017.

[10] J. W. Creswel, "Research design: Qualitative, quantitative, and mixed methods approaches," Los angeles Univ. Nebraska-Lincoln, 2009.

[11] W. L. Neuman, Social Research Methods: Qualitative and Quantitative Approaches. Essex: 
Pearson Education Limited, 2014. 